\title{
Effect of Stress on the Work Ability of Aging American Workers: Mediating Effects of Health
}

\author{
Tianan Yang ${ }^{1,2}$, Taoming Liu ${ }^{1,2}$, Run Lei ${ }^{1,2}$, Jianwei Deng ${ }^{1,2}$ and Guoquan $\mathrm{Xu}^{1,2, *}$ \\ 1 School of Management and Economics, Beijing Institute of Technology, Beijing 100081, China \\ 2 Sustainable Development Research Institute for Economy and Society of Beijing, Beijing 100081, China \\ * Correspondence: guoquanxu@bit.edu.cn; Tel.: +86-10-68918492; Fax: +86-10-68912483
}

Received: 29 May 2019; Accepted: 24 June 2019; Published: 27 June 2019

\begin{abstract}
We examined how stress affects the work ability of an aging workforce, how health mediates this relationship, and how the effects of stress on work ability differ in relation to social status. We analyzed data from the Health and Retirement Survey, namely, 2921 observations in 2010, 2289 observations in 2012, and 2276 observations in 2014. Ongoing chronic stress, social status, health status, and associations with individual work ability were assessed with ordinary least squares regression. Stress was significantly inversely associated with work ability. Health may function as a mediator between individual stress and work ability. The effects of stress and health on work ability decreased as social status increased. To cope with the challenges of aging workforces, future policy-makers should consider job resources and social status.
\end{abstract}

Keywords: work ability; stress; social status; aging workforces; health

\section{Introduction}

In industrialized countries, including the United States, maintaining the abilities of aging workers has become a popular topic in research on the long-term health of the aging workforce [1,2]. Perceived ability to work is an individual's sense of their capability and function in performing or satisfying the requirements of their positions and represents how well people cope with the demands of their job [3-6]. The most frequently discussed determinants of perceived ability to work are job stress and health, which can be explained by the Job Demands-Resources model (JD-R) [7-11]. This model assumes that job demands and job resources affect the well-being of aging workers by means of motivational and health-impairment processes and explains why reported work ability is lower among aging workers than among their younger colleagues.

Aging workers are less productive because they have less job resources to manage their job demands and because they experience cognitive changes and declines in their physiological and physical abilities [12-16]. Aging is related to decreases and changes in several physical functions [14-16] and reduces the ability to maintain homeostasis, because of reductions in processing speed, working memory, and selective attention $[17,18]$. It decreases resources available to cope with decreased physical energy, high workloads [19], and supervisor expectations. These job demands may increase stress and impair worker health, engagement and perceived ability to continue working $[2,19,20]$. Tuomi et al. found that physical and physiological capacity at age 60 years is only $60 \%$ of that at age 20 years [11]. This is attributable to the age-related decrease in the efficiency of the oxygen transport system, which is caused by decreases in maximum heart rate, stroke volume and arteriovenous oxygen difference [21]. In addition, aging is associated with changes in the circulatory system that decrease blood flow to organs and the contractile capacity of the heart and increase systolic and diastolic blood pressures [22].

If we extend the JD-R model, health, as a personal resource, can be considered an important mediator between job stress and work ability [23,24]. In the health-impairment process, job demands 
are strongly associated with job stress and thus impair employee health. In contrast, job resources, such as personal resources in the motivational process, are strongly associated with motivational outcomes such as perceived work ability. Personal resources such as health [18] can enhance employee resiliency and perceived ability and, by enabling successful control of their work environment, help workers achieve positive health outcomes in the future. Airila and colleagues reported that health, defined as a resource in everyday life, significantly enhanced employee work ability as part of the motivational process explained by the JD-R model and Conservation of Resources theory. Specifically, as age increases, age-sensitive losses (e.g., in physical fitness, health, sensory abilities, and basic cognitive functions) tend to outweigh resource gains (e.g., in knowledge, experience, and social status), and the resources of aging workforces, such as physical fitness, health, sensory acuity, multitasking ability, and functional brain efficacy, decrease throughout adulthood [4,25-27].

Most previous empirical evidence was collected in cross-sectional studies $[9,28]$ and therefore may not illustrate trends in work ability and cannot identify causal relations among investigated variables. In addition, the role of health-related resources in the JD-R model, particularly with respect to the health impairment process and motivational process $[29,30]$, has seldom been investigated. Therefore, we examined the causal relationships that explain how stress affects work ability in an aging workforce, how health mediates this association, and how the effects of stress on work ability differ in relation to social status.

\section{Methods and Materials}

\subsection{Sample}

We conducted a secondary analysis of data from the 2010 through 2014 waves of the Health and Retirement Survey (HRS) in the United States. The HRS measures health, retirement, and psychosocial factors and work ability of aging workers. The survey was funded by the National Institute of Aging and the Social Security Administration of the United States. The HRS was initiated in 1992 and used multistage area probability sampling to recruit adults older than 50 years for participation in biennial surveys. According to the description of the HRS, survey data were collected by face-to-face or phone interviews every 2 years. The sample population was divided into two groups, which were alternately surveyed. In other words, if subgroup 1 was surveyed at year $t$, subgroup 2 was surveyed at year $t+2$, while subgroup 1 was surveyed again at year $t+4$. To avoid the aging problem and a decrease in the number of participants over time, new samples were added every 6 years $[21,22]$. The variables of interest were mainly collected from a participant lifestyle questionnaire (PLQ), including the Perceived Ability to Work Scale (PAWS), stress scale, and health subjective rating [23]. Using these longitudinal data, we examined empirically the effects of ongoing chronic stressors, social status and health status on individual work ability. Detailed information on the study population and research design have been published elsewhere [24].

\subsection{Data Manipulation}

Because data for some of the target variables were not available in 2006 and 2008, we only analyzed data from 2010 through 2014 in the present longitudinal study. We then examined data quality before conducting the statistical analysis. The expectation-maximization method was used to address the problem of missing values.

After imputation, the unbalanced dataset obtained contained 7486 observations: 2921 observations for 2010, 2289 observations for 2012, and 2276 observations for 2014. Next, the final data for analysis were generated by deleting observations with unreasonable values for one or more variables. The process is shown in Figure 1.

The minimum age of HRS survey participants was 50 years; thus, the 382 observations from participants younger than 50 years were deleted. Second, three additional observations were deleted because the recorded values for the variable proxying health were outside the defined range. Third, 
we examined the values for control variables to correctly capture individual variation in characteristics potentially associated with work ability. Seventeen observations were deleted because they specified a year starting current position later than the survey year. One observation indicating 99 years of education was also deleted. Ultimately, a dataset of 7083 observations was used in the statistical analysis.

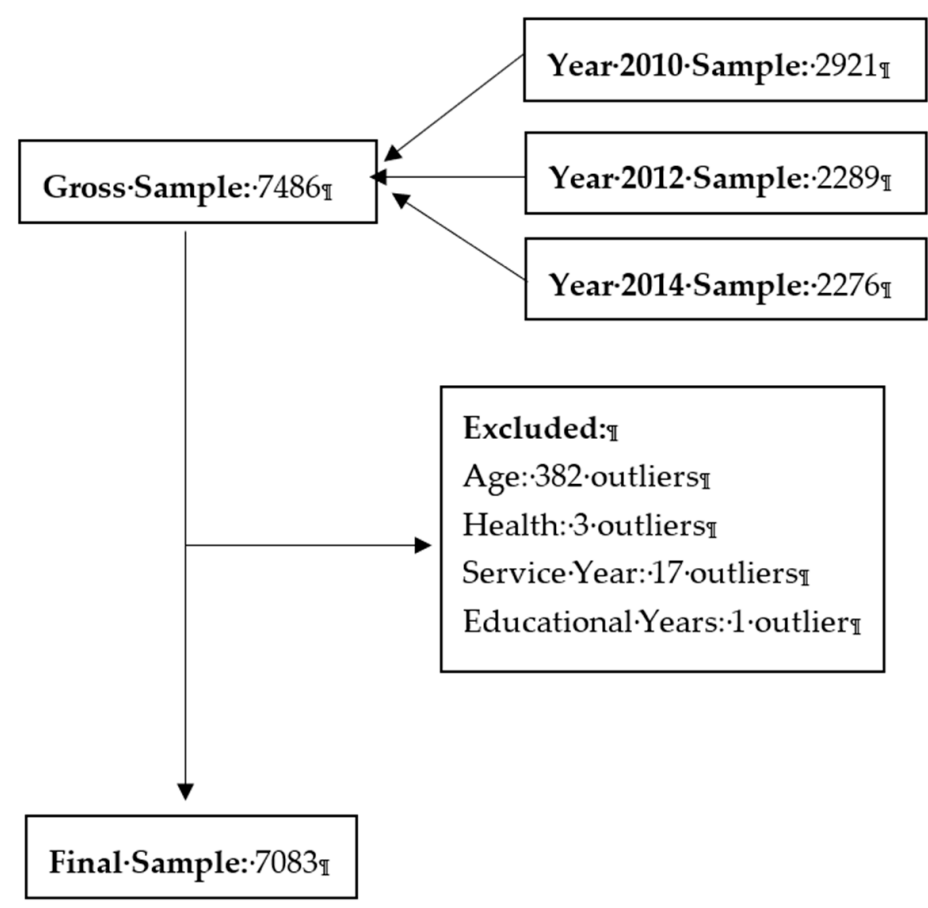

Figure 1. Framework for dataset generation.

\subsection{Definitions of Variables}

Table 1 shows the definitions of all variables. WORK, the dependent variable, refers to work ability and measures an individual's perceived ability to work. It was measured using PAWS because that instrument has been validated as a robust indicator of perceived productivity loss [18]. PAWS is a reliable and valid instrument and has acceptable psychometric properties [5]. The Cronbach $\alpha$ coefficient for PAWS was 0.89 [23] in both the HRS Psychosocial Working Group and the present study. The PAWS consists of four items, e.g., "How many points would you give your current ability to work?" (Table 2). Each item is rated from 0 (cannot currently work at all) to 10 (work ability is currently at its lifetime best). Higher values for work ability score represent greater work ability. We used the total score of the four questions. STRESS refers to stress and was measured using the six items of the "Ongoing Chronic Stressors" [25], e.g., "Ongoing difficulties at work". Each item was rated on a four-point scale $(1=$ No, did not happen; 2 = Yes, but not upsetting; $3=$ Yes, somewhat upsetting; $4=$ Yes, very upsetting). Higher values reflect greater stress. The Cronbach $\alpha$ for this scale was $0.64-0.71$ for the HRS Psychosocial Working Group [23] and 0.73 for the present study. This instrument has acceptable psychometric properties [25]. In this study, the logarithm of the total score for the eight questions on stress was used to investigate the association between ongoing stress and work ability. People differ in their perception of their social status, which in turn affects their work ability [26,31,32]. To examine the effect of perceived social status on work ability, SOCIAL was constructed by using the score of the PLQ question to measure subjective social status. Because our study focuses on the work ability of older workers, health status is more likely to be related to work ability [18]. Thus, we used the HEALTH from the HRS question ("Would you say your health is excellent, very good, good, fair, or poor?") to investigate the association with work ability. 
Table 1. Definitions of variables.

\begin{tabular}{|c|c|}
\hline Variable & Definition \\
\hline WORK & $\begin{array}{l}\text { The total score of } 4 \text { questions in the HRS measuring perceived work ability. Each } \\
\text { question was scored from } 0 \text { to } 10 \text { with respect to a job's separate general, physical, } \\
\text { mental, and interpersonal demands. High scores indicate high work ability. }\end{array}$ \\
\hline STRESS & $\begin{array}{l}\text { The natural logarithm of the total score for } 8 \text { ongoing chronic stressors in the HRS } \\
\text { survey. The score ranges from } 1 \text { to } 4 \text { for each question, and illustrates various stresses } \\
\text { with respect to ongoing health issues of the respondent, physical or emotional } \\
\text { problems in spouses or children, problems with alcohol or drug use in a family } \\
\text { member, difficulties at work, financial strain, housing problems, relationship problems, } \\
\text { and helping sick, limited, or frail family members or friends. High scores indicate high } \\
\text { stress. }\end{array}$ \\
\hline SOCIAL & $\begin{array}{l}\text { Social status, as perceived by the individual. High scores indicate high self-perceived } \\
\text { social status. }\end{array}$ \\
\hline HEALTH & $\begin{array}{l}\text { Health status of an individual in the survey year. The original score ranges from } 1 \text { to } 5 \text {, } \\
\text { with lower values indicating better health status. We subtracted the original values } \\
\text { from } 5 \text {, to make them more readable in the regression results. Higher scores thus } \\
\text { indicate better health status. }\end{array}$ \\
\hline GENDER & $\begin{array}{l}\text { An indicator variable of the gender of an individual. Originally, } 1 \text { represented male } \\
\text { and } 2 \text { represented female. We replaced the value of } 2 \text { with } 0 \text {. Thus, } 1 \text { indicates male; } \\
\text { other values indicate female. }\end{array}$ \\
\hline AGE & The natural logarithm of the age of an individual. \\
\hline WORKLOAD & $\begin{array}{l}\text { An indicator variable that controls for differences in the workload of an individual. The } \\
\text { classification process is as follows; if the original work hours per week is lower than } 10 \text {, } \\
\text { the value is } 1 \text {; if } 10 \leq \text { work hours } \leq 20 \text {, the value is } 2 \text {; if } 20<\text { work hours } \leq 30 \text {, the value } \\
\text { is } 3 \text {; if } 30<\text { work hours } \leq 40 \text {, the value is } 4 \text {; if work hours }>40 \text {, the value is } 5 \text {. }\end{array}$ \\
\hline EXPERIENCE & $\begin{array}{l}\text { The natural logarithm of the respondent's years of service in a job. Years of service was } \\
\text { calculated as the natural logarithm of the difference between the year the respondent } \\
\text { started the current job and the survey year. }\end{array}$ \\
\hline EDUCATION & The total number of years of education an individual has received. \\
\hline
\end{tabular}

Table 2. Descriptive Statistics of Variables.

\begin{tabular}{|c|c|c|c|c|c|c|c|}
\hline Variable * & $N(\%)$ & Mean & SD & Min & $25 \%$ & $75 \%$ & Max \\
\hline \multicolumn{8}{|l|}{ GENDER } \\
\hline Women & $5880(83.0)$ & & & & & & \\
\hline Men & $1203(17.0)$ & & & & & & \\
\hline \multicolumn{8}{|l|}{ WORKLOAD } \\
\hline$<10$ h/week & $268(3.8)$ & & & & & & \\
\hline 10-20 h/week & $490(6.9)$ & & & & & & \\
\hline 20-30 h/week & $860(12.1)$ & & & & & & \\
\hline 30-40 h/week & $3728(52.6)$ & & & & & & \\
\hline$>40 \mathrm{~h} /$ week & $1737(24.5)$ & & & & & & \\
\hline WORK & & 34.57 & 5.29 & 0.00 & 32.00 & 39.00 & 40.00 \\
\hline STRESS & & 12.54 & 3.85 & 8.00 & 10.00 & 15.00 & 32.00 \\
\hline SOCIAL & & 6.46 & 1.59 & 1.00 & 5.00 & 8.00 & 10.00 \\
\hline HEALTH & & 2.51 & 0.95 & 0.00 & 2.00 & 3.00 & 4.00 \\
\hline AGE & & 60.69 & 7.36 & 50.00 & 55.00 & 65.00 & 99.00 \\
\hline EXPERIENCE & & 20.21 & 14.47 & 0.00 & 7.00 & 32.00 & 83.00 \\
\hline EDUYEARS & & 13.65 & 2.76 & 0.00 & 12.00 & 16.00 & 17.00 \\
\hline
\end{tabular}

* See Table 1 for variable definitions.

To capture differences in work ability caused by other personal characteristics, we included controls categorized into two groups. The first group was related to demographic characteristics. An individual's ability to meet the physical needs of a job may diminish with advancing age [2]. Therefore, AGE was constructed to measure the logarithm of the respondent's age. We calculated respondent age by subtracting the year they responded to the survey by the year of their birth. For gender, although there was no significant difference in work ability between male and female workers $[27,28]$, we included GENDER as a control, because the association might differ in relation 
to age group. The variable GENDER classifies males and females and was constructed to indicate sex differences in multivariate analysis. The second control group was related to occupational characteristics. A longitudinal study found that a decrease in the work ability of aging workers was related to a "reduced working hours" policy [29]. To control for such a difference, we constructed the variable WORKLOAD by classifying original working hours into five levels. We did this because of the presence of extreme values in the dataset. WORKLOAD defines five levels of workload based on working hours per week, without the need to delete or minorize the data. An aging worker with more work experience in a position might have greater work ability [30,33]. Therefore, EXPERIENCE, i.e., the logarithm of the difference between the year respondents started their current job and the survey year, was used in our analysis. Because educational background also affects an individual's work ability [34], the variable EDUCATION (i.e., total years of education received by an individual) was used as a proxy of educational background [35].

\subsection{Method}

As shown in Figure 2, we present an empirical model that uses ordinary least squares regression to evaluate ongoing chronic stress (STRESS), social status (SOCIAL), health status (HEALTH), and associations with individual work ability (WORK). The model is used to examine the effects of variables of interest on work ability, after controlling for variables previously identified as potential confounders in the analysis of work ability. The regression analysis of work ability is mathematically expressed below.

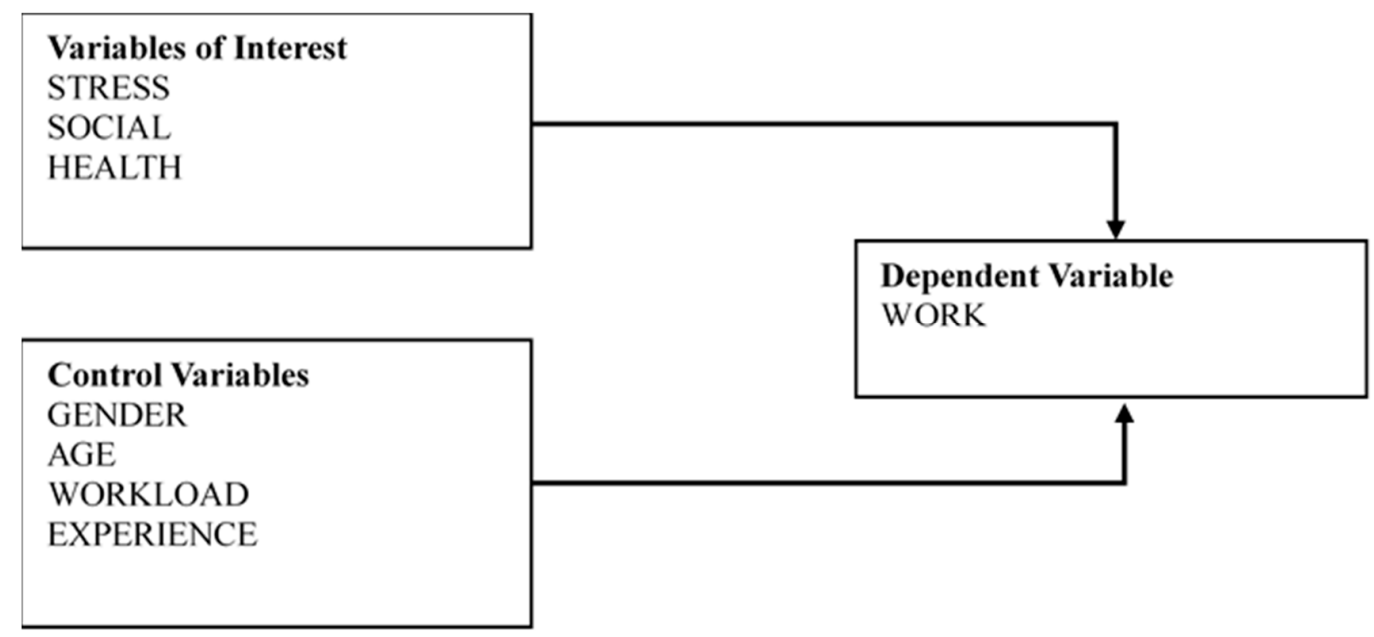

Figure 2. Empirical design.

The subscript it is associated with individual $i$ in year $t$. Because we collected longitudinal data for our model, we calculate heteroscedasticity-robust standard errors for our fixed effects regression model. The year fixed effects are included to capture other variation, such as job market changes over time, which affects work ability.

To examine the mediation effects of HEALTH [36], we designed a path model, as shown in Figure 3. Along with Equation (1), we used Equations (2) and (3) to examine mediation effects.

$$
\begin{aligned}
& \text { WORK }_{i t}=\beta_{0}+\beta_{1} \text { STRESS }_{i t}+\beta_{2} \text { SOCIAL }_{i t}+\beta_{3} \text { HEALTH }_{i t}+\beta_{4} \text { GENDER }_{i t}+ \\
& \beta_{5} \text { AGE }_{i t}+\beta_{6} \text { WORKLOAD }_{i t}+\beta_{7} \text { EXPERIENCE }_{i t}+\beta_{8} \text { EDUCATION }_{i t}+\mu_{i t} \\
& \begin{aligned}
\text { WORK }_{i t}=\gamma_{0} & +\gamma_{1} \text { STRESS }_{i t}+\gamma_{2} \text { SOCIAL }_{i t}+\gamma_{3} \text { GENDER }_{i t}+\gamma_{4} \text { AGE }_{i t} \\
& +\gamma_{5} \text { WORKLOAD }_{i t}+\gamma_{6} \text { EXPERIENCE }_{i t}+\gamma_{7} \text { EDUCATION }_{i t} \\
& +\epsilon_{i t}
\end{aligned}
\end{aligned}
$$




$$
\begin{aligned}
\text { HEALTH }_{i t}= & \alpha_{0}+\alpha_{1} \text { STRESS }_{i t}+\alpha_{2} \text { SOCIAL }_{i t}+\alpha_{3} \text { GENDER }_{i t}+\alpha_{4} \text { AGE }_{i t} \\
& +\alpha_{5} \text { WORKLOAD }_{i t}+\alpha_{5} \text { EXPERIENCE }_{i t}+\alpha_{5} \text { EDUCATION }_{i t} \\
& +\theta_{i t}
\end{aligned}
$$

First, we ran the regression according to Equation (2) to yield the coefficient $\gamma_{1}$ between STRESS and WORK. Second, we determined the significance of $\gamma_{1}$. If $\gamma_{1}$ is not significant, no mediation effect is present. Otherwise, we ran a regression according to Equation (3) to yield the coefficient, $\alpha_{1}$, between STRESS and WORK. The third step was to determine the significance of $\alpha_{1}$ in Equation (3) and $\beta_{3}$ in Equation (1). If at least one was not significant, we used the Sobel test to identify mediation effects. If both were significant, we examined whether HEALTH was a partial or full mediator, by examining coefficient $\beta_{1}$ in Equation (1). A significant $\beta_{1}$ indicates partial mediation, and a nonsignificant $\beta_{1}$ indicates full mediation.

These methods yield the total effect measured by $\gamma_{1}$, the natural direct effect measured by $\beta_{1}$, and the natural indirect effect measured by the product of $\alpha_{1}$ and $\beta_{3}$.

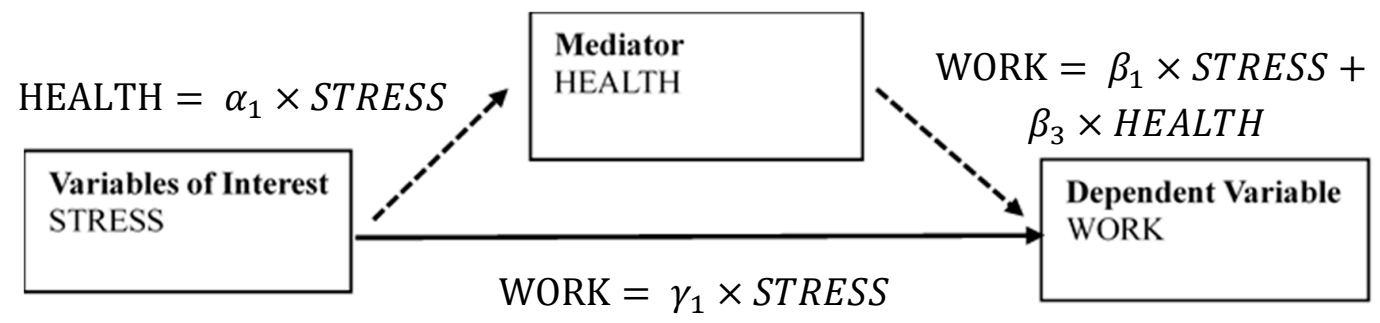

Figure 3. Mediation model design.

\section{Empirical Results}

\subsection{Descriptive Statistics}

Demographic information was missing for a few participants $(0.9 \%$ to $8.7 \%$ of the overall population). Table 2 shows the descriptive statistics for all variables used in the model. For the variables STRESS, AGE, and EXPERIENCE, we used the logarithm of the original values, to improve normality for regression purpose, but report raw values here. The actual value for WORK ranged from 0 to 40 . The average score, 34.57 , illustrates the high work ability of respondents.

We observed heterogeneity of variables of interest in the sample. The original score for ongoing chronic stressors (STRESS) ranged from 8 to 32 in the sample, with an average of 12.54 and a standard deviation (SD) of 3.85. Similarly, the average score for SOCIAL was 6.46 (SD 1.59). The average value for health was 2.51, and the SD was even larger. Among the controls, $83 \%$ of respondents were female. The actual range for AGE was 50 to 99. As for WORKLOAD, most respondents worked full time, and one quarter worked more than 40 hours per week. Regarding EXPERIENCE, the actual value ranged from 0 to 83 years of experience in the current job; the average was 20 years (SD 14.57). Regarding EDUCATION, the respondents received 13.65 years of education on average, and the range was 0 to 17 years.

\subsection{Correlation Matrix}

Table 3 shows the correlation matrix for the variables. The lower left section shows Spearman correlation coefficients and the upper right section shows Pearson correlation coefficients. The correlations of work ability (WORK) with variables of interest were generally higher than those for other variables, indicating potential associations between dependent and independent variables. The correlations among other variables were much lower, except for those between WORKLOAD and AGE as well as between HEALTH and EDUCATION. Multicollinearity does not appear to be a significant issue, since the largest correlation is 0.343 . Multicollinearity was confirmed with variance inflation factors, the highest of which was less than 2 . 
Table 3. Correlation coefficients for variables.

\begin{tabular}{|c|c|c|c|c|c|c|c|c|c|}
\hline Variable & 1 & 2 & 3 & 4 & 5 & 6 & 7 & 8 & 9 \\
\hline 1. WORK & 1 & $-0.288 * *$ & $0.248^{* * *}$ & $0.343^{* * *}$ & $-0.051^{* * *}$ & $-0.102^{* * *}$ & $0.133^{* * *}$ & $0.020 *$ & $0.152 * * *$ \\
\hline 2. STRESS & $-0.257^{* * *}$ & 1 & $-0.296^{* * *}$ & $-0.304 * * *$ & $-0.071^{* * *}$ & $-0.105^{* * *}$ & 0.015 & $-0.076^{* * *}$ & $-0.040^{* * *}$ \\
\hline 3. SOCIAL & $0.224 * * *$ & $-0.281 * * *$ & 1 & $0.278^{* * *}$ & $0.059 * * *$ & $0.124 * * *$ & $0.056 * * *$ & $0.140 * * *$ & $0.267 * * *$ \\
\hline 4. HEALTH & $0.320 * * *$ & $-0.300 * * *$ & $0.269 * * *$ & 1 & -0.013 & $-0.027 * *$ & $0.062 * * *$ & $0.032 * * *$ & $0.275^{* * *}$ \\
\hline 5. GENDER & $-0.076^{* * *}$ & $-0.066^{* * *}$ & $0.062 * * *$ & -0.012 & 1 & $0.208^{* * * *}$ & $0.031^{* * *}$ & $0.105^{* * *}$ & 0.013 \\
\hline 6. AGE & $0.106^{* * *}$ & $-0.093^{* * *}$ & $0.117^{* * *}$ & -0.018 & $-0.172^{* * *}$ & 1 & $-0.330^{* * *}$ & $0.210^{* * *}$ & -0.005 \\
\hline 7. WORKLOAD & $0.119 * * *$ & 0.013 & $0.079 * * *$ & $0.072 * * *$ & $0.035 * * *$ & $-0.281^{* * *}$ & 1 & $0.084^{* * *}$ & $0.063 * * *$ \\
\hline 8. EXPERIENCE & 0.009 & $-0.066 * * *$ & $0.130^{* * *}$ & $0.040 * * *$ & $0.088^{* * *}$ & $0.150 * * *$ & $0.114^{* * *}$ & 1 & $0.045^{* * *}$ \\
\hline 9. EDUCATION & $0.129^{* * *}$ & $-0.038^{* * *}$ & $0.301^{* * *}$ & $0.256^{* * *}$ & 0.019 & 0.000 & $0.095^{* * *}$ & $0.057^{* * *}$ & 1 \\
\hline
\end{tabular}

The lower left section shows Spearman correlation coefficients; the upper right section shows Pearson correlation coefficients. The numbers 1 to 9 represent the variables of WORK through EDUCATION. See Table 1 for variable definitions. ${ }^{*}, * *, * * *: p<0.1,0.05$, and 0.01 , respectively. 


\subsection{Regression Analysis}

Table 4 shows the results of our main regression model. We regress WORK on STRESS, SOCIAL, HEALTH, and other control variables. As shown in column 1, the controls explained no more than $5 \%$ of the variation in work ability (WORK). After including the variables of interest, $\mathrm{R}^{2}$ increased to $19.30 \%$, illustrating the statistical significance of explanatory variables. Autocorrelation was checked with the Durbin-Watson Test. The value was about 2, which indicates that autocorrelation is not a concern.

Table 4. Regression analysis of factors affecting work ability.

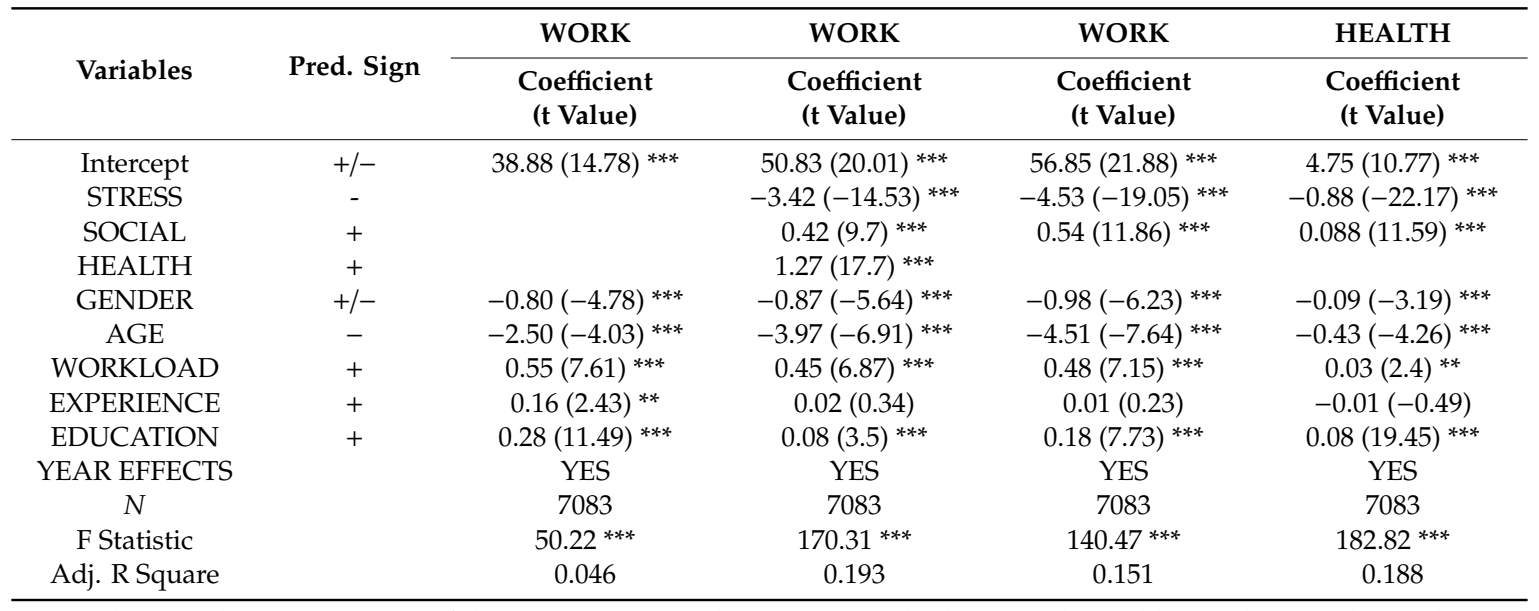

Column 1 shows the results of the regression model containing only the control variables. Column 2 shows the results of the regression model containing the variables of interest and controls. Columns 1-3 show the results of regression models (1)-(3) for mediation analysis; the dependent variable is HEALTH. ${ }^{*},{ }^{* *},{ }^{* * *}: p<0.1,0.05$, and 0.01 , respectively.

The coefficient of STRESS ( $\beta=-0.1043, p<0.01)$ was significantly negatively associated with work ability (WORK); a one percent increase in STRESS decreased work ability score by about 0.0342 points. The coefficient of social status (SOCIAL) was significantly positively associated with WORK; a one-point increase in SOCIAL increased work ability by 0.42 points. The positive coefficient for the third variable of interest indicates that a one-point increase in HEALTH increased work ability (WORK) by 1.27 points.

With respect to the control variables, the negative coefficient for gender showed that, after age 59 years, work ability was lower among men than among women. The coefficient between WORKLOAD and work ability (WORK) was positive and statistically significant, which suggests that a person able to work more hours per week has greater work ability. The significant positive coefficient of EDUCATION confirmed the findings of prior studies, which reported that education improves work ability. However, the coefficient between experience (EXPERIENCE) and work ability was not significant.

\subsection{Mediation Analysis}

Health status (HEALTH) may function as a mediator between stress and work ability [37]. In accordance with prior studies, we conducted additional statistical analysis to identify potential mediation effects. Using previously described procedures, we ran the regression model in Equation (2), the results of which are shown in column 3 of Table 4. The coefficient of STRESS on WORK, $\gamma_{1}$, was significant. Therefore, we ran the regression model in Equation (3), which yielded a significant coefficient of STRESS on HEALTH, $\alpha_{1}$, as shown in column 4 of Table 4 . The coefficient of HEALTH on WORK, $\beta_{3}$, was also significant, as was the coefficient for STRESS on WORK, $\beta_{1}$, which confirmed the presence of partial mediation effects. The total effects-i.e., direct effects plus indirect effects-are shown in Table $5 ; 24.5 \%$ of the total effect was mediated by HEALTH. 
Table 5. Identification of mediation effects.

\begin{tabular}{cc}
\hline Effect & Coefficient Value \\
\hline Total Effect $\left(\gamma_{1}\right)$ & -4.53 \\
Direct Effect $\left(\beta_{1}\right)$ & -3.42 \\
Indirect Effect $\left(\alpha_{1} \times \beta_{3}\right)$ & -1.11 \\
Percent of total effect that is mediated & $24.50 \%$ \\
\hline
\end{tabular}

When a person has high social status, he/she may have more money, receive more education, and obtain a better job, among other advantages. Therefore, he/she may be more capable of meeting job demands. Besides, since they may have the best jobs and more resources, the stress may not affect an individual's work ability in the same way. To examine such differences in the effects of stress, the sample was divided into three groups based on scores for subjective social status (SOCIAL). Low social status was defined as a score of 3 or lower, high social status as a score of 8 or higher, and moderate social status as a score of 4 to 7 . The results of this subgroup analysis are shown in Table 6. Columns 1 to 3 list the coefficients for low, moderate, and high social status. The effects of stress on work ability decreased as social status increased. The coefficient for STRESS was -6.11 for the low social status group and only -2.90 for the high social status group, which suggests that stress has greater effect on work ability when social status is low. Similarly, people with relatively low social status have less job resources to assist them with job demands. Work therefore requires greater attention and energy, which is harmful to their health. The effects on health also decreased with increasing social status, as indicated by JDR model and the decrease in the coefficient for HEALTH from 2.47 to 0.96 . In sum, the work performance of workers with low social status was more vulnerable to STRESS and HEALTH.

Table 6. Regression analysis of work ability in relation to subjective social status.

\begin{tabular}{ccccc}
\hline \multirow{2}{*}{ Variables } & Pred. Sign & Low & Moderate & High \\
\cline { 2 - 4 } & & $\begin{array}{c}\text { Coefficient } \\
\text { (t Value) }\end{array}$ & $\begin{array}{c}\text { Coefficient } \\
\text { (t Value) }\end{array}$ & $\begin{array}{c}\text { Coefficient } \\
\text { (t Value) }\end{array}$ \\
\hline Intercept & $+/-$ & $49.38(2.72)^{* * *}$ & $53.05(16.5)^{* * *}$ & $52.14(12.74)^{* * *}$ \\
STRESS & - & $-6.11(-4.31)^{* * *}$ & $-3.72(-13.34)^{* * *}$ & $-2.90(-6.79)^{* * *}$ \\
HEALTH & + & $2.47(6.16)^{* * *}$ & $1.34(15.1)^{* * *}$ & $0.96(8.47)^{* * *}$ \\
GENDER & +- & $-1.19(-1.05)$ & $-0.89(-4.37)^{* * *}$ & $-0.87(-3.75)$ \\
AGE & - & $-1.87(-0.45)$ & $-3.93(-5.4)^{* * *}$ & $-3.48(-3.81)^{* * *}$ \\
WORKLOAD & + & $0.50(1.16)$ & $0.50(5.93)^{* * *}$ & $0.41(4.04)^{* * *}$ \\
EXPERIENCE & + & $-0.05(-0.15)$ & $0.06(0.81)$ & $-0.01(-0.13)$ \\
EDUCATION & + & $0.08(0.54)$ & $0.12(4.13)^{* * *}$ & $0.08(1.91)^{*}$ \\
YEAR EFFECTS & & YES & YES & YES \\
N & & 296 & 4768 & 2019 \\
F Statistic & & $10.29 * * *$ & $98.83^{* * *}$ & $36.44^{* * *}$ \\
Adj. R Square & & 0.2208 & 0.1559 & 0.1365 \\
\hline
\end{tabular}

This table shows the results of regression models examining the effects of stress on work ability in relation to social status. ${ }^{*}{ }^{* * *}: p<0.1$ and 0.01 , respectively.

As shown in Table 7, we also examined the mediation effects among the groups with different social status by using the procedures of mediation effects analysis. Because all related coefficients are significant for each group, HEALTH is a partial mediator for all groups. However, by examining the percent of total effect that is mediated, we find that HEALTH mediates more of the total effects for groups with lower social status. 
Table 7. Identification of mediation effects for subgroups.

\begin{tabular}{cccc}
\hline \multirow{2}{*}{ Effect } & Low & Moderate & High \\
\cline { 2 - 4 } & Coefficient Value & Coefficient Value & Coefficient Value \\
\hline Total Effect $\left(\gamma_{1}\right)$ & -8.73 & -4.95 & -3.79 \\
Direct Effect $\left(\beta_{1}\right)$ & -6.11 & -3.72 & -2.90 \\
Indirect Effect $\left(\alpha_{1} \times \beta_{3}\right)$ & -2.62 & -1.23 & -0.89 \\
Percent of total effect that is mediated & $30.01 \%$ & $24.85 \%$ & $23.50 \%$ \\
\hline
\end{tabular}

\subsection{Robustness Check}

As a robustness check, we replaced WORKLOAD—a variable with five levels for workload per week-with the natural logarithm of working hours per week in our main regression. The results (not tabulated) were qualitatively and quantitatively similar to those in our main analysis.

We analyzed longitudinal data in this study; thus, STRESS may have been endogenously determined as a result of reverse causality. While we found that the ratio of STRESS was associated with diminished work ability, a person with lower work ability may be more likely to have greater stress. To test the robustness of our results, we regressed WORK on the lagged variables STRESS, SOCIAL and HEALTH. LAGWORK was also included, as there may be some "stickiness" in individual work ability. As shown in Table 8, the results were consistent with those shown in column 2 of Table 4 . The coefficient for LAGWORK was significant and positive, illustrating the baseline trend in work ability, while the coefficients for LAGSOCIAL became nonsignificant. The significant results for the lagged terms STRESS and HEALTH suggest that the effects of stress and health on work ability persist over time.

Table 8. Regression analysis of work ability with lagged independent variables.

\begin{tabular}{cccc}
\hline \multirow{2}{*}{ Variables } & \multirow{2}{*}{ Pred. Sign } & WORK & HEALTH \\
\cline { 3 - 4 } & & Coefficient (t Value) & Coefficient (t Value) \\
\hline Intercept & +- & $20.75(3.10)^{* * *}$ & $2.24(1.97)^{* *}$ \\
LAGWORK & & $0.49(11.04)^{* * *}$ & \\
LAGSTRESS & - & $-0.12(-3.06)^{* * *}$ & $-0.07(-10.59)^{* * *}$ \\
LAGSOCIAL & + & $-0.02(-0.22)$ & $0.07(4.22)^{* * *}$ \\
LAGHEALTH & + & $0.53(3.60)^{* * *}$ & \\
GENDER & +- & $-0.75(-1.78)^{*}$ & $-0.15(-1.86)^{*}$ \\
AGE & - & $-1.34(-0.90)$ & $-0.07(-0.29)$ \\
WORKLOAD & + & $0.16(1.25)$ & $0.04(1.48)$ \\
EXPERIENCE & + & $0.13(0.94)$ & $0.00(0.16)$ \\
EDUCATION & + & $0.07(1.46)$ & $0.07(7.92)^{* * *}$ \\
YEAR EFFECTS & & YES & YES \\
$N$ & & 1462 & 1462 \\
F Statistic & & $60.05 * * *$ & $44.77 * * *$ \\
Adj. R Square & & 0.271 & 0.173 \\
\hline
\end{tabular}

This table shows the results of regression models examining the effects of stress on work ability with lagged variables. Column 2 shows the results of the regression model containing variables of interest and controls. Column 3 shows the results of the regression model for mediation analysis; the dependent variable is HEALTH. ${ }^{*}{ }^{* *},{ }^{* * *}: p<0.1,0.05$, and 0.01 , respectively.

\section{Discussion}

In this study, chronic stress, social status, health status, and associations with individual work ability were assessed with ordinary least squares regression. Analysis of the longitudinal data showed that stress was persistently significantly inversely associated with work ability. Health mediated the relationship between individual stress and work ability, and the effects of stress and health on work ability decreased as social status increased. 
Our first contribution was to use longitudinal empirical data to examine the causal relationship between stress, health and work ability and the mediating effects of health. As was the case in previous studies $[38,39]$, stress was significantly negatively associated with work ability (WORK) in this longitudinal study, which supports a consistent effect of stress on work ability. In addition, heath was significantly positively associated with work ability. A one unit increase in health score improved work ability by 1.27 points. Ultimately, health mediated the relationship between stress and work ability. Extension of the JD-R model [38] to the health-impairment process suggests that health helps employees cope with stress at the workplace and motivates their perceived ability as part of a motivational process. Health-as a type of job resource-mediates the effects of stress on work ability because it allows workers to satisfy the demands of work and employers at workplaces. The mediating role of health and its relative resources in the JD-R model, from the perspectives of the health-impairment and motivational process, has been thoroughly investigated in longitudinal empirical studies and should be considered in future research and practice.

Our second contribution is to provide empirical evidence regarding the impact of social status on work ability. The coefficient of social status (SOCIAL) was significantly positively associated with work ability, which suggests that higher self-perceived social status improves work ability. Semi-elasticity showed that a one-point increase in social status score improved work ability by 0.42 points (average work ability score increased from 34.57 to 34.99). This result is consistent with the findings of Demakakos et al. [31] and Singh-Manoux et al. [32]. The JD-R model helps explain the effects of social status. Work conditions can be divided into job demands and job resources. Job demands require sustained physical and/or psychological effort or skills. Job resources reduce job demands and the associated physiological and psychological costs; stimulate personal growth, learning, and development; and help workers achieve work goals [40,41]. A person with high social status may have more resources, such as more money, a high level of education and a better job, among other benefits $[31,32,34,42,43]$. Such persons may therefore be more capable of meeting job demands. In addition, because they may have the best jobs and more resources, stress may not affect their work ability in the same way. Rizzuto and colleagues (2012) reported that individuals with higher educational attainment and those involved in highly complex and challenging jobs seemed to be more resilient. These characteristics were more common among persons with high social status [44].

Our third contribution was to confirm the effects of control variables on work ability. First, as in previous studies $[2,29,34]$, age was significantly negatively associated with work ability, while education and workload were significantly positively associated. This is plausible because as workers age they may feel less capable of meeting the physical demands of a specific position. These older workers might have greater difficulties accepting or learning new skills, because of rapid economic or technological development [3]. In addition, aging workers with more years of education are able to handle a greater workload, which suggests that they have more social and health-related resources to cope with their job demands. To explain why the finding that EXPIERIENCE was not significantly associated with work ability is not consistent with previous studies [30,33], two plausible causes were given: On the one hand, although work experience in the current job varied greatly in the sample, it was difficult to determine if a person had performed similar jobs before, which could diminish the effect of current experience. On the other hand, older workers may have been assigned to positions that do not require extensive experience, which in turn decreased the effects of experience.

Our findings imply that further attention to health, stress and other psychosocial factors is of considerable importance in enhancing the performance of aging workers and in closing the gap between workforce supply and demand. Managers must acknowledge the central role of health among aging workforces, identify the true stressors and internal mechanisms by which stress impairs worker health and work ability and control these risk factors as part of the policy making process. For instance, to increase the productivity of an enterprise, policies must consider how to improve worker health and control the adverse effects of work-family imbalance and related psychosocial factors on health and work ability among aging workers, particular those of low social status and low workload. Then, 
specific interventions can be developed and implemented to help workers effectively cope with these stressors and to promote health in organizations.

This study has four limitations. First, because the data used were secondary, we were unable to collect information on some important variables of interest. Second, some respondents died of illnesses or other conditions, which resulted in survival bias in our study. Third, our use of self-reported questionnaires rather than quantitative measures limits the generalizability of our conclusions. Finally, the use of log-transformed values in the analysis might limit the generalizability of our conclusions.

\section{Conclusions}

Aging workers have less job resources and extremely high job demands, which resulted in high levels of stress. In this longitudinal study, we noted a persistent significantly negative relationship between stress and work ability and that this relationship was significantly mediated by health status, which was relatively poor among aging workers. Finally, stress had a weaker effect on the work ability of aging workers with high social status.

Author Contributions: T.Y. and G.X. conceived and designed the study. T.Y., T.L., R.L., J.D., and G.X. contributed to data collection, data management, statistical analysis, interpretation of the results, and revision of the manuscript. T.Y. wrote the paper. All authors reviewed the paper, provided significant feedback, and approved the final manuscript.

Funding: This research was funded by the National Natural Science Foundation of China (grant no. 71603018, 71804009, 71432002, 91746116), the Beijing Social Science Foundation (grant no. 17JDGLB008, 17GLC043), the Ministry of Education in China Project of Humanities and Social Sciences (grant no. 16YJC630017), the Special Plan for Basic Research of Beijing Institute of Technology (grant no. 20192142002, 20182142001), the Beijing Institute of Technology Research Fund Program for Young Scholars (grant no. 2015CX04038), and the Special Fund for Joint Development Program of Beijing Municipal Commission of Education.

Conflicts of Interest: The authors declare no conflicts of interest.

\section{References}

1. Walker, A. Managing an Ageing Workforce: A Guide to Good Practice; European Foundation for the Improvement of Living and Working Conditions: Dublin, Ireland; Office for Official Publications of the European Communities: Luxembourg, 1999.

2. Ilmarinen, J. The ageing workforce-Challenges for occupational health. Occup. Med. 2006, 56, 362-364. [CrossRef]

3. OECD. Reforms for an Ageing Society; Sourceoecd Social Issues/Migration/Health; OECD: Paris, France, 2000; pp. 1-220.

4. Redaymulvey, G. Working Beyond 60: Key Policies and Practices in Europe. Ind. Labor Relat. Rev. 2007, 60, 85.

5. Ilmarinen, J.; Rantanen, J. Promotion of work ability during ageing. Am. J. Ind. Med. 1999, 36, $21-23$. [CrossRef]

6. Supporting the aging workforce: A review and recommendations for workplace intervention research. Annu. Rev. Organ. Psychol. Organ. Behav. 2015, 2, 351-381. [CrossRef]

7. Maertens, J.A.; Putter, S.E.; Chen, P.Y.; Diehl, M.; Huang, Y.H. Physical Capabilities and Occupational Health of Older Workers. In The Oxford Handbook of Work and Aging; Oxford University Press: Oxford, UK, 2012. [CrossRef]

8. Blok, M.; De Looze, M.P. What is the evidence for less shift work tolerance in older workers. Ergonomics 2011, 54, 221-232. [CrossRef]

9. Hedge, J.W.; Borman, W.C. Work and aging. In The Oxford Handbook of Organizational Psychology; Oxford University Press: London, UK, 2012; pp. 1245-1283.

10. Lichtman, S.M. The physiological aspects of aging. In Fourteen Steps in Managing an Aging Workforce; Dennis, H., Ed.; Lexington Books: Lexington, MA, USA, 1988; pp. 39-51.

11. Soto, C.J.; John, O.P. Development of big five domains and facets in adulthood: Mean-level age trends and broadly versus narrowly acting mechanisms. J. Personal. 2012, 80, 881-914. [CrossRef] 
12. Soto, C.J.; John, O.P.; Gosling, S.D.; Jeff, P. Age differences in personality traits from 10 to 65: Big Five domains and facets in a large cross-sectional sample. J. Personal. Soc. Psychol. 2011, 100, 330-348. [CrossRef]

13. Zwart, B.C.H.D.; Frings-Dresen, M.H.W.; Dijk, F.J.H.V. Physical workload and the ageing worker: A review of the literature. Int. Arch. Occup. Environ. Health 1996, 68, 1-12. [CrossRef]

14. Topcic, M.; Baum, M.; Kabst, R. Are high-performance work practices related to individually perceived stress? A job demands-resources perspective. Int. J. Hum. Res. Manag. 2016, 27, 45-66. [CrossRef]

15. Costa, G.; Sartori, S. Ageing, working hours and work ability. Ergonomics 2007, 50, 1914-1930. [CrossRef]

16. Costanza, R.; Kubiszewski, I.; Giovannini, E.; Lovins, H.; Mcglade, J.; Pickett, K.E.; Ragnarsdóttir, K.; Roberts, D.; De, V.R.; Wilkinson, R. Development: Time to leave GDP behind. Nature 2014, 505, 283-285. [CrossRef]

17. Goetzel, R.Z.; Long, S.R.; Ozminkowski, R.J.; Hawkins, K.; Wang, S.; Lynch, W.L. Health, Absence, Disability, and Presenteeism Cost Estimates of Certain Physical and Mental Health Conditions Affecting, U.S. Employers. J. Occup. Environ. Med. 2004, 46, 398-412. [CrossRef]

18. Vänni, K.; Virtanen, P.; Luukkaala, T.; Nygård, C.-H. Relationship between perceived work ability and productivity loss. Int. J. Occup. Saf. Ergon. 2012, 18, 299-309. [CrossRef]

19. Mcgonagle, A.K.; Fisher, G.G.; Barnes-Farrell, J.L.; Grosch, J.W. Individual and work factors related to perceived work ability and labor force outcomes. J. Appl. Psychol. 2015, 100, 376-398. [CrossRef]

20. Koolhaas, W.; Klink, J.J.L.V.D.; Boer, M.R.D.; Groothoff, J.W.; Brouwer, S. Chronic health conditions and work ability in the ageing workforce: The impact of work conditions, psychosocial factors and perceived health. Int. Arch. Occup. Environ. Health 2014, 87, 433. [CrossRef]

21. National institutes of Health U.S. Department of Health and Human Services. Growing Older in America: The Health and Retirement Study; Karp, F., Ed.; National Institutes of Health U.S. Department of Health and Human Services: Bethesda, MD, USA, 2007.

22. Health and Retirement Study. Produced and Distributed by the University of Michigan with Funding from the National Institute on Aging (Grant Number NIA U01AG009740); ([2010 HRS core]); Health and Retirement Study, Ed.; Health and Retirement Study: Ann Arbor, MI, USA, 2010.

23. Smith, J.; Fisher, G.; Ryan, L.; Clarke, P.; House, J.; Weir, D. Psychosocial and Lifestyle Questionnaire 2006-2010 Documentation Report Core Section LB; The HRS Psychosocial Working Group, Ed.; University of Michigan: Ann Arbor, MI, USA, 2013.

24. Juster, F.T.; Suzman, R. An Overview of the Health and Retirement Study. J. Hum. Res. 2016, 30, S7-S56. [CrossRef]

25. Troxel, W.M.; Matthews, K.A.; Bromberger, J.T.; Kim, S.T. Chronic stress burden, discrimination, and subclinical carotid artery disease in African American and Caucasian women. Health Psychol. Off. J. Divis. Health Psychol. Am. Psychol. Assoc. 2003, 22, 300-309. [CrossRef]

26. Löve, J.; Holmgren, K.; Torén, K.; Hensing, G. Can work ability explain the social gradient in sickness absence: A study of a general population in Sweden. BMC Public Health 2012, 12, 163. [CrossRef]

27. López, P. Aging and work ability from the gender perspective. Revista Cubana de Salud y Trabajo 2010, 11, 48-53.

28. Padula, R.S.; da Silva Valente Ldo, S.; de Moraes, M.V.; Chiavegato, L.D.; Cabral, C.M. Gender and age do not influence the ability to work. Work 2012, 41, 4330-4332.

29. Meer, L.V.D.; Leijten, F.R.M.; Heuvel, S.G.V.D.; Ybema, J.F.; Wind, A.D.; Burdorf, A.; Geuskens, G.A. Erratum to: Company Policies on Working Hours and Night Work in Relation to Older Workers' Work Ability and Work Engagement: Results from a Dutch Longitudinal Study with 2 Year Follow-Up. J. Occup. Rehabil. 2016, 26, 182. [CrossRef]

30. Chung, J.; Park, J.; Cho, M.; Park, Y.; Kim, D.; Yang, D.; Yang, Y. A study on the relationships between age, work experience, cognition, and work ability in older employees working in heavy industry. J. Phys. Ther. Sci. 2015, 27, 155-157. [CrossRef]

31. Demakakos, P.; Nazroo, J.; Breeze, E.; Marmot, M. Socioeconomic status and health: The role of subjective social status. Soc. Sci. Med. 2008, 67, 330-340. [CrossRef]

32. Archana, S.-M.; Marmot, M.G.; Adler, N.E. Does Subjective Social Status Predict Health and Change in Health Status Better Than Objective Status? Psychosom. Med. 2005, 67, 855-861.

33. Ghaddar, A.; Ronda, E.; Nolasco, A. Work ability, psychosocial hazards and work experience in prison environments. Occup. Med. 2011, 61, 503-508. [CrossRef] 
34. Mirowsky, J.; Ross, C.E. Education, Social Status, and Health; Aldine Transaction: Plano, TX, USA, 2003; pp. 71-125.

35. Jussi, I. Work ability-a comprehensive concept for occupational health research and prevention. Scand. J. Work Environ. Health 2009, 35, 1-5.

36. Iacobucci, D. Mediation analysis and categorical variables: The final frontier. J. Consum. Psychol. 2012, 22, 582-594. [CrossRef]

37. Bojana, K.; Milan, M.; Rajna, G.; Ljiljana, B.; Andrea, R.; Jadranka, M. Work-related stress and work ability among Croatian university hospital midwives. Midwifery 2011, 27, 146-153.

38. Airila, A.; Hakanen, J.J.; Schaufeli, W.B.; Luukkonen, R.; Punakallio, A.; Lusa, S. Are job and personal resources associated with work ability 10 years later? The mediating role of work engagement. Work Stress 2014, 28, 87-105. [CrossRef]

39. Williamson, D.L.; Carr, J. Health as a resource for everyday life: Advancing the conceptualization. Crit. Public Health 2009, 19, 107-122. [CrossRef]

40. Bakker, A.B.; Demerouti, E. The Job Demands-Resources model: State of the art. J. Manag. Psychol. 2007, 22, 309-328. [CrossRef]

41. Demerouti, E.; Bakker, A.B.; Nachreiner, F.; Schaufeli, W.B. The job demands-resources model of burnout. J. Appl. Psychol. 2001, 86, 499-512. [CrossRef]

42. Dahl, E. Social mobility and health: Cause or effect? BMJ Clin. Res. 1996, 313, 435-436. [CrossRef]

43. Simandan, D. Rethinking the health consequences of social class and social mobility. Soc. Sci. Med. 2018, 77, 258-261. [CrossRef]

44. Tracey, E.R.; Katie, E.C.; Jared, A.L. The aging process and cognitive abilities. In The Oxford Handbook of Work and Aging; Oxford University Press: Oxford, UK, 2012; pp. 236-255.

(C) 2019 by the authors. Licensee MDPI, Basel, Switzerland. This article is an open access article distributed under the terms and conditions of the Creative Commons Attribution (CC BY) license (http://creativecommons.org/licenses/by/4.0/). 